\title{
ADULT STILL'S DISEASE PROGRESSING TO NONRADIOGRAPHIC AXIAL SPONDYLOARTHRITIS (AJA-AXNX) - A CASE REPORT
}

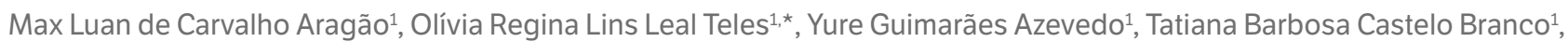
Lina Oliveira de Carvalho ${ }^{1}$, Regina Adalva de Lucena Couto Océa ${ }^{1}$, Mônica Valéria Siqueira Santana de Vechi ${ }^{1}$, José Caetano Macieira ${ }^{1}$

1.Universidade Federal de Sergipe, Aracaju (SE), Brazil.

*Corresponding author: oliviaa.teles@gmail.com

\section{BACKGROUND}

Adult Still's disease (ASD) is a rare inflammatory disorder of unknown etiology, characterized by fever, arthritis and rash. In its evolution, there are no reports of axial sacroiliac involvement as seen in nonradiographic axial spondyloarthritis (AJA-axNx). The present report aims to discuss the case of a patient who developed EpAs after clinical presentation of ASD.

\section{CASE REPORT}

A 22-year-old male patient, who started 9 months ago with polyarthritis (MCFs, wrists and elbows), daily afternoon fever, weight loss (12 kg/6 months) and evanescent maculopapular exanthema. Symptomatology triggered after a previous episode of nonsuppurative pharyngotonsillitis. During the investigation, leukocytosis was identified $>20,000$ (with $83 \%$ neutrophils), erythrocyte sedimentation rate: $123 \mathrm{~mm} / 1 \mathrm{st} \mathrm{h}$, C-reactive protein: $160 \mathrm{mg} / \mathrm{dL}$, elevation of transaminases, ferritin: $1675 \mathrm{ng} / \mathrm{mL}$; rheumatoid factor, ANA and viral serology nonreactive. After exclusion of possible differential diagnoses, it was concluded that the patient had ASD. He was submitted to corticotherapy, after 30 days, weaned from the drug, and started methotrexate 10 mg weekly, with later increase. Concomitantly to the withdrawal of prednisone, the patient evolved with arthritis (right wrist/ipsilateral shoulder), inflammatory back pain (VAS: 10) and enthesitis (1st and 7th intercostal spaces, anterosuperior iliac crest and calcaneus) with good response to the use of NSAIDs. Continued investigation, HLA-B27: negative; pelvic X-ray: normal and pelvic MRI: bilateral sacroiliitis. The patient was treated with infliximab, with remission of the axial and peripheral symptoms.

\section{CONCLUSION}

This is a case of ASD as a trigger for spondyloarthritis.

\section{KEYWORDS}

Spondyloarthritis, Adult Still's disease, Nonradiographic. 